ИЗВЕСТИЯ АҚАДЕМИИ НАУК ЭСТОНСКОН ССР. ТОМ 29 ГЕОЛОГИЯ. 1980, № 3

\title{
НЕКОТОРЫЕ ОБЩИЕ ВОПРОСЫ СТРАТИГРАФИИ СИЛУРИЙСКОЙ СИСТЕМЫ
}

\begin{abstract}
Фундаментальное значение стратиграфии в геологии в настоящее время стало еще более явным, причем в равной мере в геологической картографии, геолого-разведочном деле и во всех научных исследованиях, связанных с геологией. Поэтому закономерно, что Стратиграфическая комиссия Международного союза геологических наук и ее подкомиссии (и рабочие группы), в частности подкомиссия по стратиграфии силура (ПСС), созданная в 1972 г. на геологическом конгрессе в Монтреале и значительно активизировавшаяся под председательством проф. Ч. Холланда (Ирландия) после конгресса в Сиднее (1976 г.), внесли большой вклад в усовершенствование общей стратиграфической шкалы (ОСШ) .

ПСС провела письменный обмен мнениями по важнейшим общим проблемам стратиграфии силурийской системы и с 30 марта по 11 апреля 1979 г. полевую сессию-экскурсию для ознакомления со стратотипическими разрезами разных подразделений силура Великобритании.* В результате этого и продолжительных дискуссий сложились некоторые общие точки зрения и выявились вопросы, требующие продолжения основательного изучения. Все достигнутые во время полевой сессии соглашения были впоследствии подтверждены официальным голосованием, проведенным письменно среди членов подкомиссии. Следует еще отметить важнейшее значение для работы ПСС, консультативного стратиграфического совещания по общим вопросам стратиграфии на примере ордовика и силура, проведенного АН СССР в 1977 г. в Алма-Ате и Москве (труды опубликованы в «Изв. АН КазССР, сер. геол.»; № 4-5 за 1979 г.). ПСС планирует представить свои предложения по усовершенствованию ОСШ силура геологическому конгрессу в 1984 г. Поэтому считаем полезным привлечь внимание советских стратиграфов к некоторым общим вопросам стратиграфии силурийской системы и наряду с приводимой информацией об итогах работы ПСС высказать и свою точку зрения.
\end{abstract}

\section{Проблема подразделений высшего ранга}

Британские острова являются типовой областью выделения силурийской и ордовикской систем. Эти важнейшие стратиграфические подразделения, с которыми связаны многие виды полезных ископаемых, обще-

\footnotetext{
* Два первых автора настоящей работы участвовали в этой сессин-экскурсии,
} 
приняты во всем мире. Однако почти полуторавековая геологическая практика на континентах Европы, Азии, Америки, Австралии и Африки показала, что британский стратиграфический стандарт не имеет полностью завершенной разработки в иерархическом плане, вызывает необходимость в альтернативных подходах и, как международный хроностратиграфический стандарт, нуждается в совершенствовании с учетом опыта, накопленного в других странах.

Стратиграфическая система входит в категорию общих (=хроностратиграфических) подразделений. В ходе становления ОСШ она оказалась основной ее единицей. Согласно существующей иерархии подразделений ОСШ за системой следует более низкое по рангу подразделение - отдел, которому в литературе на английском языке соответствует термин «series».

Исторически сложилось так, что все системы, за исключением ордовика и силура, делятся на два или на три отдела (например, нижняя и верхняя пермь; нижний, средний и верхний кембрий). Каждый отдел согласно представлениям многих советских стратиграфов отвечает особому этапу в развитии Земли (см. Стратиграфический кодекс СССР). Правда, не по всем системам имеется единогласие специалистов. Так, например, наряду с общепринятым делением перми на два отдела существуют предложения о выделении в ее составе трех отделов. В силурийской системе в силу сложившихся традиций в отдельных странах и на разных языках в настоящее время используются в основном три варианта подразделения силура: двучленное деление на нижний и верхний силур, трехчленное деление на нижний, средний и верхний силур и деление на четыре отдела, имеющих собственные названия. Наиболее распространенной при этом является британская номенклатура названий отделов (лландовери, венлок, лудлов, даунтон), а также свешанная (англо-чешская, англо-польская и др.).

Большей частью эти отделы, по существу, являются местными сериями, возведенными в ранг отделов. Так, например, в США до недавнего времени использовались три подразделения силура: нижний, средний и верхний, а фактически это были провинциальные серии Oswegan (= Alexandrian), Niagaran и Cayugan. Однако в последние годы американские стратиграфы отказались от такого деления из-за плохой палеонтологической характеристики стратотипов и стали применять британское четырехчленное деление (вместо даунтона - пржидоли; Berry, Boucot, 1970). Такая же тенденция наблюдается и в Австралии (Talent и др., 1975).

В Канаде и Китае выделяются те же четыре подразделения, но группируются в три отдела: нижний = лландовери, средний $=$ венлок, верхний = лудлов + даунтон (или пржидоли) (Jackson и др., 1978).

В СССР с 1951 г. официально принято относить к нижнему силуру отложения, эквивалентные британским сериям Llandovery и Wenlock, а к верхнему силуру - отложения эквивалентные сериям Ludlow и Downton (что отвечает в чешской схеме ярусам Kopanina и Přidoli).

Примерно такое же деление силура на две части сформировалось на разрезах Баррандиена (Liten и Budnan; Horny, 1962). Оно отражает прежде всего региональную специфику - нижнее подразделение представлено преимущественно граптолитовыми сланцами, а верхнее в основном известняками.

Но существует и другая точка зрения: нижнему силуру соответствует только Llandoverian (= Valentian), а верхнему силуру - Salopian (эта точка зрения отражена в «Геохронологической таблице»

3 TA Toimetised. G 31980 
F. W. B. Eusinga, 1975 и др.) или, корректнее, Wenlockian, Ludlowian и Pridolian (Poole и др., 1977). Близкий этому вариант предложен Н. П. Кульковым и А. Б. Ивановским (1978). Нам кажется первая точка зрения (по которой граница отделов проводится по кровле венлока) более логичной, строгой и оправдывающей себя в геологической практике такой страны как СССР. Она принимается и во многих странах Европы.

Каждый из вариантов расчленения обосновывается специфической аргументацией. Например, по некоторым данным, граница между лландовери и венлоком по сравнению с другими границами характеризуется более резкими эволюционными изменениями в таких группах как, например, трилобиты, ругозы, брахиоподы (см. Елкин, 1974а, б; Кульков, Ивановский, 1978); на границе венлока и лудлова наблюдаются наибольшие в силуре изменения в комплексах граптолитов (Rickards, 1978), a с началом пржидола связано появление таких растений (в том числе представителей рода Cooksonia), которые, по мнению M. А. Сенкевич (1975), знаменуют принципиально новый - девонский этап в развитии флоры. Однако было бы опрометчиво ориентироваться только на бросающиеся в глаза яркие моменты в развитии отдельных групп органического мира.

Многолетний опыт работы международных и национальных стратиграфических комиссий показал, что такие аргументы недостаточно убедительны для специалистов по другим группам фауны или по другим регионам. Для успешного использования их необходимы всесторонний анализ и обобщение материала в мировом масштабе, подобно тому, как было сделано Международным комитетом по установлению границы силура и девона (см. Martinsson (Ed.), 1977) и как начато по определению границы между ордовиком и силуром.

Как видно из приведенного краткого обзора, схема первоочередного расчленения силура основывается на небольшом числе подразделений: лландовери, венлок, лудлов и «четвертое подразделение» (даунтон, пржидоли, скала, подляс). Следовательно, вопрос о дву-, трех- или четырехчленном подразделении силура, кроме того, является вопросом о ранге названных стратонов.

К сожалению, имеющиеся кодексы или стратиграфические руководства не дают четкого основания для определения ранга стратона, позволяющего установить с какой единицей имеется дело - отделом или ярусом. Но если подходить к стратиграфии силура с позиций единообразия ОСШ в целом и сравнительной продолжительности геологических периодов (и соответственно их подразделений), то, кажется, правильнее рассматривать лландовери, венлок и другие, отмеченные выше подразделения, как ярусы, а не как отделы.

В таком случае, мы должны допустить, что все названные подразделения более или менее одинакового объема, хотя обычно считается, что лландовери по объему соответствует чуть ли не всей остальной части силура, а пржидоли представляет собой вообще очень короткий промежуток времени. Такое предположение базируется на палеонтологических и седиментологических данных и приводит к выводу о необходимости провести ревизию ранга рассматриваемых подразделений дифференцированно. Однако седиментометрические данные по методу П. П. Зотова (см. Романовский, 1977) указывают на примерно одинаковую продолжительность главных подразделений силура в пределах 8-9 млн. лет (следует отметить, что нам не известно, каким принят автором объем «верхнелудловскогож яруса). К сожалению, имеющиеся 
датировки абсолютного возраста силурийских отложений в целом недостаточны для суждения о продолжительности веков (см. Spjeldnaes, 1978) и лишь последние определения P. Дж. Pocca и других (Ross и др., 1978), можно считать, подтверждают указанную выше продолжительность венлока и лудлова, но для лландовери более вероятным является примерно 13 млн. лет. Попутно отметим, что по анализу, проведенному В. В. Меннером (1979), эти цифры. лишь немного выше средней длительности накопления отложений яруса.

Требование соразмерности и аналогия подразделений разных систем представляются важными объективными критериями в вопросе о ранге подразделений, но, как и в отношении палеонтологических критериев или таковых на основе литологической цикличности, они не являются абсолютными. В такой сложной обстановке ПСС в апреле 1979 г. пришла к компромиссному выводу, что желательно использовать неофициальное подразделение силурийской системы на нижний и верхний силур, в составе которых выделяются по два отдела.

В отношении названий последних большинство членов подкомиссии согласилось использовать термины «венлок» и «лудлов», тогда как названия первого и четвертого отделов остались открытыми.

\section{О стандартных ярусах}

Легко заметить, что в ОСШ сейчас нет официально принятых подразделений ярусного ранга. Действительно, Llandovery, Wenlock, Ludlow и Downton обозначаются термином «series», что должно соответствовать понятию «отдел». Более дробные подразделения в британской шкале, помимо зон, были сугубо местными (Wenlock Shales, Kirkby Moor Flags и т. п.). И только сравнительно недавно (Holland и др., 1963; Cocks и др., 1970; Bassett и др., 1975) первые три отдела были подразделены на ярусы (stages).

Однако исторически сложилось так, что в СССР и в очень многих других странах мира к этому времени уже утвердились представления, что именно британские «series» являются типами стандартных ярусов. Это было вызвано тем, что они по своему положению в ОСШ, а также по палеонтологическому содержанию аналогичны таким подразделениям как живет, фран, турне, визе, имеющим статус ярусов ОСШ.

Что же представляют собой «stages» британской шкалы силура? Как известно в лландовери их выделено четыре (Rhuddanian, Idwian, Fronian и Telychian), в венлоке - два (Sheinwoodian и Homerian) и в лудлове - четыре (Eltonian, Bringewoodian, Leintwardinian и Whitcliffian). По своему характеру они, несомненно, являются хроностратиграфическими, но разномасштабными подразделениями, в чем можно легко убедиться, если сравнить, например, Bringewoodian и Sheinwoodian. Наряду с хорошо коррелируемыми подразделениями (например, в Прибалтике сравнительно легко выделяются подразделения лландовери и венлока) установлены ярусы, корреляционное значение которых весьма сомнительное.

В британском руководстве по стратиграфической процедуре (Holland (Ed.), 1978) для возможного обозначения подобных подразделений совершенно правильно приводится термин «региональный ярус» (regional stage). В СССР этому понятию целиком отвечает термин «горизонт» или же реже употребляемый «региоярус» (regiostage). Региоярус (горизонт) нередко совпадает по своему объему со стандартным 
ярусом ОСШ, но часто последнему в региональной стратиграфической схеме отвечает несколько региональных ярусов.

Региоярусы (горизонты) - важнейшие региональные корреляционные стратиграфические подразделения, интегрирующие в регионе (седиментационном бассейне) одновозрастные отложения с различной палеонтологической и литологической характеристиками. Во многих случаях эти подразделения могут быть потенциальными стандартами ярусов ОСШ, но нельзя все региональные ярусы рассматривать как хроностратиграфические подразделения в том смысле, какой сейчас вкладывается в хроностратиграфическую шкалу как систему общих стандартных подразделений ОСШ. Это скорее «банк» важнейших региональных стратиграфических эталонов «ярусной группы», который в дальнейшем может быть использован для отбора лучших типов стандартных ярусов или паратипов.

Таким образом, британские ярусы правильнее сейчас рассматривать в качестве региональных ярусов (горизонтов). Их, безусловно, следует подвергнуть детальному анализу на предмет возможного признания в качестве ярусов стандартной шкалы.

Прошедшая полевая сессия ПСС приняла в этом отношении ряд существенных решений: во-первых, совещание признало важнейшее значение горизонтов (региоярусов) для региональной стратиграфии и их самостоятельность наряду со стандартными ярусами; во-вторых, признано желательным определять стандартные ярусы на базе британских разрезов в стратотипической области силура. Если они окажутся неподходящими, то следует искать типы в других регионах, а британским ярусам останется роль региоярусов.

Конкретно по ярусам лландовери было высказано мнение, что их характеристика и изученность не соответствуют требованиям; предложено провести дополнительное изучение, а одновременно ознакомиться и с некоторыми другими разрезами (например, о. Антикости), могущими претендовать на роль стратотипа.

Подразделение венлока на два яруса проводится согласно предложению М. Г. Бассетта и др. (Bassett и др., 1975) - шейнвудский внизу (с нижней границей по подошве зоны C. centrifugus, она же служит подошвой венлока; стратотипом границы избран разрез на берегу ручья Хагли у фермы Лизовс в районе Венлок) и гомерский вверху (с нижней границей по подошве зоны C. lundgreni).

Границу между венлоком и лудловом предложено проводить на уровне границы между свитой Мач Венлок (бывший так наз. венлокский известняк) и нижне-элтонскими слоями в стратотипическом разрезе Питш Коппис. Все новые находки граптолитов подтверждают, что этот уровень достаточно хорошо соответствует подошве зоны $\mathrm{N}$. nilssoni.

Несмотря на сравнительно хорошую изученность и прекрасную обнаженность стратотипического района Лудлова, выделенные ранее четыре подразделения (Holland и др., 1963) - элтон, бринжвуд, лейнтвордайн и витклифф - в качестве стандартных ярусов не были приняты (оставлены в качестве литостратиграфических единиц). Решено подразделять лудлов на два яруса с границей между ними по подошве M. leintwardinensis. Ч. Холланд, Дж. Лоусон и В. Волмсли предложили для них новые названия по стратотипам района Лудлова: для нижнего яруса - горстиан (Gorstian), верхнего - лудфордиан (Ludfordian). 


\section{Название верхнего яруса (или отдела) силура}

Трудности межрегиональной корреляции верхов силура, существовавшие до недавнего времени, в настоящем в основном уже преодолены. По крайней мере, они не вызывақт столь острых дискуссий. Установлено также, что в верхней части силура достаточно четко обособляется самостоятельное подразделение в ранге яруса (или отдела), для которого используются разные названия - скальский, пржидольский, подлясский. Наибольшую популярность из них получил пржидоли. В этом же значении все чаще употребляется и даунтон. Однако при этом уже начали возникать недоразумения корреляционного порядка (см. Kaljo, 1978).

Первоначально даунтон был выделен фактически как верхняя часть лудлова (Lapworth, 1880). Переопределенная даунтонская серия в coвременном объеме включает и значительно более высокие стратиграфические уровни, чем прежде, но зато из ее состава исключены отложения, составляющие первоначальный лудлов. Тем самым был сохранен приоритет на объем лудлова в ущерб даунтону.

Сейчас все больше становится ясным, что пржидоли, если его понимать как стратиграфический интервал от основания зоны M. ultimus до основания зоны M. uniformis, примерно соответствует даунтону Лэпворса (Елкин, 1974а) или, точнее, используя современную британскую стратиграфическую схему, подошва пржидоли проходит внутри слоев Витклиф (примерно в середине или несколько выше) верхов лудлова (Kaljo, 1978), а кровля лишь предположительно совмещается с подошвой псаммостеусового известняка в низах диттонского яруса (Holland, Richardson, 1977).

Недавно Н. П. Кульков и А. Б. Ивановский (1978) показали, что главные претенденты на четвертый ярус, по существу, представлены отложениями трех разных макрофаций верхов силура: даунтон - прибрежно-лагунными, пржидоли - раковинными, подляс - граптолитовыми отложениями.

Руководствуясь практической целесообразности, авторы предлагают считать типовыми стратоны, базирующиеся на разрезах раковинных отложений. В таком случае предпочтение следует отдавать термину «пржидоли». Несомненно, в пользу пржидоли говорит и его связь со стратотипом границы силура и девона, а также популярность в последние годы. По данным опроса членов ПСС, 26 предпочитали пржидоли (6 из них с разными резервациями), 5 - даунтон, 2 - подолий и 1 седлец + подляс.

Однако, к сожалению, этот вопрос не решается так просто. Во-первых, название даунтон имеет неоспоримый приоритет (некоторые изменения объема подразделения не влияют на это), даунтон следует лудлову в одном стратотипе без каких-либо проблем корреляции, тогда как кровля лудлова и подошва пржидоли находятся на разных уровнях (эти подразделения несколько перекрываются; см. Lawson, 1971; Kaljo; 1978), что вызывает необходимость в переопределении объема одного из них при использовании этих двух названий в качестве стандартных. Наконец, А. Мартинссон (Martinsson, 1977) на основе изучения остракод показал, что нижняя граница даунтона в смысле возможностей корреляции не так уж плоха как часто думалось. Новые данные по некоторым другим группам, в частности телодонтам и акритархам, подтверждают его выводы (Каратаюте-Талимаа, 1978; Мярсс, в печати; Holland, Richardson, 1977 и др.). Одновременно следует помнить 
недостаточную изученность перехода копанина/пржидоли (Chlupaс̌ и др., 1972) и довольно сложную картину литологических и биостратиграфических соотношений, выявленную П. Шенлаубом и его коллегами (устное сообщение).

Следовательно, дилемма даунтон или пржидоли (или даже трилемма, при участии других претендентов) остается в силе и требует решения в ближайшие годы. Для подготовки этого совещание ПСС в апреле 1979 г. рекомендовало организовать три рабочие группы, которым надлежит в течение года составить обзоры по даунтону, пржидоли и подолию (скальскому ярусу).

\section{Стабильность шкалы и региональные исследования}

Наша главная задача заключается в создании стабильной общей стратиграфической шкалы (ОСШ), которая, оставаясь иерархически целостной, обеспечивала бы полную сравнимость результатов, получаемых при изучении силурийских отложений в разных частях мира, и не сковывала бы свободу региональных исследований. Сравнимость результатов является непременным условием любых глобальных геохронологических синтезов (картографических, палеотектонических, по проектам МПГК и др.). Именно по этой причине не может быть оправдано одновременное существование трехчленного силура в одних и двучленного в других странах, да еще с несопоставимыми внутренними границами. Не может быть лудловского яруса (если таковой получит признание) в понимании британских стратиграфов и в понимании советских или чешских стратиграфов, как это еще недавно было. Содержание таких общих понятий везде должно быть одинаковым.

Вместе с тем международный канон не должен оказывать давление на стратиграфические концепции и процедуры, складывающиеся при региональных исследованиях. Задача последних - отразить с максимальной возможностью и полнотой естественный ход историко-геологических и историко-биологических событий в пределах того или иного географического пространства, ограниченного определенной геологической спецификой (древний седиментационный бассейн, структурнофациальная зона, палеобиогеографический пояс и т. д.). Глобальные закономерности хода естественно-исторических событий еще должны быть вскрыты (вероятно, они существуют), а региональные совершенно очевидны уже сейчас. Только так.можно понимать содержание и цели региональной стратиграфии и региональных стратиграфических исследований; это совсем не литостратиграфия или частная биозональная стратиграфия, как иногда думают.

Региональная стратиграфня - основа основ всей стратиграфии и источник тех стратиграфических эталонов (общих стратиграфических подразделений и их типовых границ лимитотипов - limitotype), из которых производится монтаж общей международной стратиграфической шкалы. По этой причине последнюю нельзя понимать как голую абстракцию; она по частям и в целом - продукт региональной стратиграфии, отражающей геологическое время.

Концентрация нашего внимания на силурийской системе Британских островов лучше всего иллюстрирует эту смысль. Эта система, установленная как чисто региональная стратиграфическая единица, и получившая дальнейшую стратиграфическую детализацию также в пределах Британских островов, - неотделимая часть общей стратиграфической шкалы вплоть до зон $(=$ хронозон $)$. Но этот фақт не означает: 
1) что типовой регион оказался самым лучшим в мире и 2) что нельзя выходить за пределы британского региона в поисках более удовлетворительного решения тех или иных вопросов, важных для построения стандартной шкалы (ОСШ). Опыт решения проблемы, связанной с определением границы силура и девона, обусловивший полностью новый взгляд на место в шкале даунтонской серии и даунтонского яруса, должен быть всегда перед нами.

Однако типовой регион системы и большинство ее подразделений остаются типовыми по сей день и этим он отличается от любых других регионов распространения силурийских отложений. Поэтому, вводя изменения в региональную стратиграфию силура Британских островов, Стратиграфический комитет Лондонского геологического общества, вероятно, должен в какой-то мере учитывать, как эти изменения могут сказаться на эффективности использования ОСШ силурийской системы, принадлежащей уже геологам всего мира.

Подчеркивая два аспекта в изучении силурийской стратиграфии Британских островов, необходимо также отметить исключительную важность глубокого знакомства экспертов подкомиссии по стратиграфии силура с важнейшими разрезами других стран мира. Подлинная ценность основных стратиграфических подразделений системы и их границ может быть выяснена только путем сравнительных исследований. Для этого необходимо выявить и изучить ключевые (опорные) разрезы на всех континентах. Наши современные знания в этой области не являются достаточно детальными и точными. Пополнение этого пробела одна из задач проекта МПГК «Экостратиграфия».

\section{ЛИТЕРА Т У А}

Елкин Е. А. Эволюционные последовательности трилобитов и ярусное деление верхнего силура. - В кн.: Этюды по стратиграфии. М., 1974а, 162-168.

Ел ки н Е. А. Древнейшие дехенеллиды. - В кн.: Древнейшие дехенеллиды (трилобиты) и стратиграфия силура Горного Алтая. Новосибирск, 19746, 64-90.

К а рат аюте -Т али м а В. Н. Телодонты силура и девона СССР и Шпицбергена. Вильнюс, 1978.

К ульков Н. П., Ив а новски й А. Б. Стратиграфические подразделения силура. Геол. и геофиз., 1978, 9, 23-30.

Р ом а н о в с к ий С. И. Седиментологические основы литологии. Л., 1977.

С енкевич M. А. Этапность развития органического мира на границе силура и девона. - В кн.: Материалы по палеонтологии среднего палеозоя урала и Қазахстана. Тр. Ин-та геол. и геохим. УНЦ АН СССР, 1975, 117, 119-126.

Стратиграфический кодекс СССР. Л., 1977.

М я р с с Т. Биозоны вертебрат (силур Северной Прибалтики), - В кн.: Сообщества и биозоны в силуре Прибалтики. Таллин (в печати).

B a ssett, M. G., Cocks, L. R. M., Holland, C. H., Rickards, R. B., War r e n, P. T. The type Wenlock Series. - Inst. Geol. Sci., Rep., 1975, 75/13.

B e r ry, W. B. N., B o u cot, A. J. Correlation of the North American Silurian rocks. Geol. Soc. Amer., Spec, pap., 1970, 102.

Chlup ač, I., J a e ger, H., Z i km un dova, J. The Silurian-Devonian boundary in the Barrandian. - Bull. Canad. Petrol. Geol., 1972, 20, 104-174.

Cocks, L. R. M., Toghill, P., Z i egler, A. M. Stage names within the Llandovery Series, - Geol. Mag., 1970, 107, $79-87$.

Eusing a, F. W. B. Geological time scale. New York, 1975.

$\mathrm{H} 011$ a nd, C. H. (Ed.) A guide to stratigraphical procedure. - Geol. Soc. Lond., Spec. pap., 1978, 11.

Holl a nd, C. H., Law so n, J. D., W a $1 \mathrm{~ms}$ ley, V. G. The Silurian rocks of the Ludlow District, Shropshire. - Brit. Mus. Nat. Hist., Bull., 1963, 8, 3, 93-171.

Holl a nd, C. H., Rich ardso n. J. B. The British Isles. - In: The Silurian-Devonian Boundary. Intern. Union Geol, Sci., Ser. A, 1977, 5, 35- 44.

Horn y, R. Das mittelböhmische Silur. - Geologie, 1962, 11, 873-916.

Jackson, D. E., Lenz, A, C., Pedder, A, E, H, Late Silurian and Early Devonian 
graptolite, brachiopod and coral faunas from Northwestern and Arctic Canada. - Geol. Assoc. Can., Spec. pap., 1978, 17.

$\mathrm{Ka} 1 \mathrm{jo}$, D. The Downtonian or Pridolian from the point of view of the Baltic Silurian. ENSV TA Toim., Geol., 1978, 27, 5-10.

L a p w orth, C. On the geological distribution of the Rhabdophora, - Ann. Mag. Nat, Hist., ser. V, $1880,5,45-62$.

L a w s o n, J. D. Some problems and principles in the classification of the Silurian System. - In: Colloque Ord.-Sil., Brest, Sept. 1971. Mém. Bureau rech. géol. min., $1971,73,301-308$.

Martinsson, A. Palaeocope ostracodes. - In: The Silurian-Devonian Boundary. Intern. Union Geol. Sci., Ser. A, 1977, 5, 327-332.

Martinsson, A. (Ed.) The Silurian-Devonian Boundary. - Intern. Union Geol. Sci., Ser. A, 1977, 5 .

Poole, F. G., S and berg, C. A., B oucot, A. J. Silurian and Devonian paleogeography of the Western United States. - In: Paleozoic Paleogeography of the Western United States. Pacific coast paleogeogr. symp. I. Los Angeles, 1977, $39-65$.

Rickards, B. R. Major aspects of evolution of the graptolites. - Acta Palaeont. Polonica, 1978, 23, 585-594.

Ross, R. J., Naeser, C. W., I zett, G. A. et al. Fission-track dating of Lower Paleozoic volcanic ashes in British stratotypes. - U.S. Geol. Surv. Open-File, Rep., 1978, 78-701, 363-365.

S peld naes, N. The Silurian System. - In: Contributions to the Geologic Time Scale. Amer. Assoc. Petrol. Geol., Studies in geol., 1978, 6, 341-345.

T a lent, J. A., B erry, W. B. N., B ou cot, A. J. Correlation of the Silurian rocks of Australia, New Zealand, and New Guinea. - Geol. Soc. Amer., Spec. pap., 1975,150 .

Отделение геологии, геофизики и геохимии

Академии наук СССР

Ннститут геологии

Академии наук Эстонской ССР

Поступила в редакцию

Институт геологии и геофизики

СО Академии наук СССР

\section{B. SOKOLOV, D. KALJO, J. JOLKIN}

\section{SILURI LADESTU STRATIGRAAFIA OLDISI KUSIMUSI}

Stratigraafia fundamentaalne roll geoloogias on tänapäeval eriti ilmseks muutunud, seepärast pühendatakse palju tähelepanu rahvusvahelise stratigraafilise skeemi täpsustamisele. Artiklis on antud ülevaade siluri stratigraafia alamkomisjoni tegevuse tulemustest, eriti siluri liigestamisest ladestikeks ja ladejärkudeks, nende piiridest ja nomenklatuurist. Oluline on luua üheselt mõistetav rahvusvaheline stratigraafiline standardskeem, mis tagaks andmete globaalse võrreldavuse ja samal ajal ei takistaks regionaalsete seaduspärasuste selgitamist.

\section{B. SOKOLOV, D. KALJO, E. YOLKIN}

\section{SOME GENERAL PROBLEMS OF STRATIGRAPHY OF THE SILURIAN SYSTEM}

The fundamental role of stratigraphy has become nowadays particularly evident. Accordingly, the Commission on Stratigraphy of the IUGS and its subcommissions have been paying much attention to the improvement of the international stratigraphical standard scale. For the above purpose, the Subcommission on Silurian Stratigraphy (SSS) (chairman C. H. Holland) organized a written discussion and a field meeting in Great Britain from 30 March to 11 April, 1979. The paper deals with some results of the SSS, especially those needing further study. 
The main problem is connected with the division of the Silurian System into series. In the main, the following three variants are used, according to which the Silurian System is divided into: 1) two series - Lower (Llandovery + Wenlock) and Upper Silurian (Ludlow + Downton or Pridoli); however, there is also a standpoint, according to which Lower Silurian includes only Llandovery, whereas all the others belong to the Upper Silurian; 2) three series - Lower (=Llandovery), Middle (=Wenlock) and Upper Silurian (Ludlow + Downton or Přidoli); 3) four series - all the above units are regarded as series.

As can be seen, all the above classifications make use of the same main units, but differ in the interpretation of their ranks. The views on the rank problem are based on greatly different and often contradictory arguments.

Here SSS has taken the stand of a compromise, suggesting to divide the Silurian informally into two pants, both of which consist of two series. Evidently, the double division is the most expedient one (in the USSR it has been in successful use since 1951); also, considering the rank of the units at the same level in the chronostratigraphical hierarchy of other systems (e.g., the Gedinnian, etc.) and the relatively short duration of the Silurian Period (30-40 m. y.,) we prefer to use the four British series as units of stage category.

The British stages are the stratigraphical units of different bulk that partially can and partially cannot be used as standard stages. Regiostages («горизонт» in Russian) are important regional units that have an independent meaning and may acquire the status of a standard stage. In a certain sedimentary basin they integrate the formations of the same age but of a different palaeontological and lithological composition.

The solution of the name problem of the fourth Silurian series needs a detailed analysis of corresponding data, for which SSS is making preparations.

The main task is to compile a stable unambiguous international standard scale which would enable a complete comparison of data from different parts of the world and, at the same time, would not become an obstacle to regional studies aimed at the elucidation of the local geological development. The standard scale is not only an abstraction but the result of regional stratigraphy. Hence follows the importance of the study of stratotype sections in the improvement of the standand scale as well as the usefulness of the corresponding measures taken by SSS. 